\title{
Professional Development as a Process of Cultural Brokering: Positioning Coaches as Cultural Brokers
}

\author{
Tasha R. Wyatt \\ Educational Innovation Institute, Medical College of Georgia \\ E. Brook Chapman de Sousa \\ University of Hawaii \\ Sarah C. Mendenhall \\ Augusta University
}

Teachers who serve diverse students must navigate two "worlds." One world is that of standardized curricula and pedagogy and the other is culturally relevant education. To effectively navigate these worlds, teachers need assistance from "cultural brokers" who can help make sense of the tension that emerges when these two educational worlds interact. This study analyzes the work of two Center for Research on Education, Diversity, and Excellence coaches who worked as cultural brokers to help teachers integrate multiple pedagogical models. The results indicate the coaches shifted their strategies depending on teacher preferences, and helped teachers overcome constraints within their classrooms and curricula. Framing coaches as "cultural brokers" may be a useful metaphor for others assisting teachers with navigating the tension that emerges in implementing culturally relevant education.

Keywords: cultural brokering, culturally relevant education, professional development, CREDE, early childhood education

\section{Introduction}

Historically, the term cultural broker has been used to describe someone who is able to communicate and negotiate between seemingly different cultures, languages, social and political systems. Cultural brokers have a long history in sociology, but globalization has recently increased their visibility. Brokers are situated between cultural worldviews, allowing them to function as cultural mediators within communities. These individuals have been particularly helpful in situations where various groups come together with the potential for tension and conflict, including times of colonization (Wolf, 1956) and political conflict (Yohani, 2013). However, more recently, their usefulness has been noted in health care (Miklavcic \& LeBlanc, 2014; Minervino \& Martin, 2007), education (Cooper, Denner, \& Lopez, 1999; Orellana, 2009; Rothstein-Fisch, Trumbull, \& Garcia, 2009), and business (Adams, 1997; Cherro Osorio \& Best, 2015; Weiler \& Yu, 2007). In these fields, cultural brokers are most recognized for helping individuals who require navigational assistance as they come into contact with larger social systems.

Research on cultural brokering in education has focused on the teachers' role in helping bridge students' cultures with that of the school in an effort to close the cultural gap that exists between these two worlds (Sleeter, 2001). Although the need for curricular connections and validating students' cultural knowledge is cited as an important feature in pedagogical models used to teach 
culturally diverse students (Brown-Jeffy \& Cooper, 2011; Ladson-Billings, 1994), few studies recognize how difficult it is for teachers to do this effectively (Wyatt \& Chapman De Sousa, 2017). In other words, just as culturally diverse students must navigate and negotiate multiple worlds, teachers serving diverse students must navigate multiple pedagogical models.

In this study, we analyzed our work as instructional coaches from a cultural brokering framework. We worked alongside 13 early childhood teachers to help them bridge culture on two planes. First, we helped teachers navigate traditional models of education alongside a culturally relevant pedagogical model, and second, we applied our understanding of teachers' and students' home culture and language to help teachers relate to students' background knowledge. Positioning our coaching as cultural brokering provided an opportunity to better understand our work to help teachers implement culturally compatible education within more traditional approaches to teaching. Guiding this study were the following research questions: (a) What brokering strategies did we use as we assisted teachers in the implementation of the Center for Research on Education, Diversity, and Excellence (CREDE) model? (b) What patterns emerged in our use of these strategies?

\section{Conceptual Framework}

The bridging multiple worlds framework (Cooper, 2011) uses the term cultural broker to label specific individuals who assist students in navigating their educational experiences. To date, the term has not been applied to the role of professional developers who assist teachers with implementing models of education that are viewed as more appropriate for diverse students. In this study, we positioned our work as CREDE coaches as cultural brokers who assisted teachers in the navigation of two different pedagogical approaches or "worlds." Using this framework, one world is the more traditional approach, in which standardized curricula and pedagogy dominate (Sleeter, 2012). The teacher is an authority figure who prioritizes individualized achievement, maintains adherence to the curriculum, and works to establish a hierarchy of power in the classroom. At the time of this study, the teachers worked under the U.S. No Child Left Behind Act, which emphasized standards-based education and underscores this approach to teaching (Milosovic, 2007; Sleeter, 2012). Institutional implementation of standardized curricula, pedagogy and assessments can restrict teachers' ability to be responsive to the unique backgrounds, cultures, and languages of students and influence the engagement of diverse learners (Nieto, 2000).

When teachers use culturally relevant, or culture-based, pedagogy, they make links between new academic content and the background experiences students bring to classrooms (Delpit, 1995; Gay, 2000; Kana'iaupuni, Ledward, \& Jensen, 2010; Ladson-Billings, 1994). These approaches emphasize relationship-building between students and teachers. They can help teachers identify and address potential hidden biases within themselves, the curriculum and classroom interactions (Howard, 2007; Nieto, 2000).

With culturally relevant pedagogy, power is more evenly distributed across the classroom, the teacher is viewed as a coconstructor of knowledge, and the curriculum is modified to help make links to students' backgrounds and establish relevancy. These models are considered a better fit for culturally diverse students (Sleeter \& Cornbleth, 2011), who may have different patterns of participation and language practices (Nieto, 2000; Souto-Manning, 2013) as well as limited access to the mainstream values and culture espoused in neoliberal models of education.

Teachers' cultural competence, or knowledge, recognition, and use of students' diverse cultures, has consequences in terms of student achievement (Howard, 2007). Research has found that teachers who used culture-based education had more engaged students with a stronger sense of self-worth and better scores on math and reading assessments than teachers who did not use culture-based education (Kana'iaupuni et al., 2010). However, there are institutional factors, such as high-stakes 
tests and an emphasis on fidelity to packaged curriculum, that put teachers under tremendous pressure to cover content and prepare for tests, that can result in tension between traditional, standardized approaches and culturally relevant models (Dover, 2013; Nieto, 2000).

\section{Cultural Brokering}

The shift from a traditional model of education to a more culturally compatible approach, requires teachers to reconceptualize the way they interact with students, design learning activities, and integrate the curriculum with students' experiences (Wyatt \& Chapman De Sousa, 2017). Moreover, this approach to teaching is a departure from the traditional kinds of teacher preparation many teachers receive in the United States (Whipp, 2013) and thus requires teachers to navigate the implementation of these approaches.

Although cultural brokers are found throughout the educational system and have been valuable in assisting culturally and linguistically diverse students navigate their education (Cooper, 2014), they occupy many positions. All cultural brokers work as go-betweens who mediate and translate two culturally distinct realities for the purpose of reducing conflict or producing change (Michie, 2014; Press, 1969; Szasz, 1994; Wolf, 1956). Paraeducators and instructional aides are often positioned as cultural brokers because they help students make sense of curricular content and teacher expectations (Lewis, 2004; Rueda \& Genzuk, 2007). Counselors often help diverse students choose majors and ensure they are on track for graduation (Jezewski, 1995; Kim, 2006). In each circumstance, the cultural broker translates and communicates important cultural knowledge for students to move through the educational pipeline.

And yet, to be effective, cultural brokers require specific skills and sensitivities to be successful. Lewis (2004) indicated that not everyone can work in this capacity, and it takes more than a common language or shared culture. Specifically, brokers must be able to bridge, link, and mediate between groups or individuals to reduce conflict (Jezewski, 1995; Rothstein-Fisch et al., 2009), a skill that requires negotiation and perspective-taking. Brokers are thought to have the ability to face two directions to meet the needs of individuals or groups involved in the brokering process (Michie, 2014; Wolf, 1956). In some cases, brokers must anticipate potential conflicts that arise, whereby quick and informed decisions must be made about what is negotiable and what is not.

Brokers must also be able to successfully translate various cultural symbols, such as words, gestures, drawings, and pictures, for meaning (Boissevain, 1974; Singh, McKay, \& Singh, 1999). Symbol translation requires more than just translating to another language; it requires that brokers have a deep understanding of both groups' goals, norms and values to couch information in ways that are meaningful (Singh et al., 1999). It is for this reason that the finished outcome of cultural brokers is often discussed as new and "innovative" because they employ strategies that have previously gone unseen (Herzog, 1972; Paine, 1971). Furthermore, dwelling in this "in-between" state allows brokers to utilize their unique perspective and propose ideas that are novel and fresh (Havik, 2013; Press, 1969), and at the same time stay confident that they are supported by both sides involved in the brokering (Brown, 1992).

Although the literature has described the moves that cultural brokers use in education (Yohani, 2013), health sciences (Jezewski, 1995; Lomas, 2007), and elsewhere (Boissevain, 1974), research has not applied this work to professional development (PD) or with teachers learning to implement culturally compatible education. The aim of this paper is to examine the strategies we used as we assisted 13 teachers with implementing the CREDE model within a more traditional approach to education in an attempt to bridge these two worlds. 


\section{The CREDE Model}

The CREDE model is a set of pedagogical strategies developed by researchers at CREDE that serve as a guideline for teachers with culturally and linguistically diverse students. The model has been implemented across the United States (e.g., Yamauchi, Im, Lin, \& Schonleber, 2013) and internationally (Wyatt, 2011) in areas where issues of cultural diversity have surfaced and tension threatens school systems.

The CREDE model consists of five pedagogical strategies known as the Standards for Effective Pedagogy, which are principles of effective teaching and learning that maximize the amount of responsive assistance and adult-child interaction in the classroom (Tharp, Estrada, Dalton, \& Yamauchi, 2000). The standards have their roots in Vygotsky's (1978) sociocultural theory, and organizes instruction around sense-making in teacher-learner collaborations. The CREDE model has been written about extensively and is considered evidence-based practice for teaching students who are not from the mainstream culture. Moreover, it has met rigorous criteria to be included in the U.S. database for pedagogical strategies that have met standards for effective learning (Institute of Educational Sciences, 2006).

The five pedagogical CREDE Standards are (a) joint productive activity (teacher and learner collaboration), (b) language and literacy development (developing language across the curriculum), (c) contextualization (connecting to prior knowledge), (d) complex thinking (developing complex thought), and (e) instructional conversation (teaching through dialogue). In the CREDE model for early childhood, the other two standards-modeling and student directed activities-are included, although they are typically used only in indigenous education. These other two standards were incorporated because early childhood educators felt they were necessary strategies in working with preschool children (Yamauchi, Im, \& Schonleber, 2012).

To effectively implement the CREDE model, the teacher must reconceptualize teaching as responsive assistance that is given within a small group format. The hallmark of the CREDE model is the instructional conversation, in which teachers engage students in discussion on an academic topic within content that is familiar. For example, rather than reading a book to students and then asking them questions in a typical initiate-respond-evaluate pattern of teaching (Mehan, 1979), students are prompted to think about their home, school, and community before the book is read and then guided through conversation to a deeper understanding of the content they will be exposed to.

Although coaches can use any one of the Standards as an entry point into the CREDE model, our group uses the instructional conversation as a focal point to learn the other CREDE standards (Goh, Yamauchi, \& Ratliffe, 2012). Additionally, this more holistic approach seems to be easier for teachers to learn, rather than being given one standard at a time to master. And yet, implementing the CREDE model is not an easy task because it requires a shift in the teachers' focus away from a strict adherence to the curriculum and places it on the teacher, whose role is to carefully assess and assist students' changing understanding in a discussion-based model of teaching (Tharp \& Gallimore, 1988). In the CREDE model, the curriculum is still important; however, the emphasis is placed on the moves teachers make to help students access material and make sense of the curriculum, an important aspect of culturally responsive teaching (Gay, 2013).

Many teachers find it difficult to reconceptualize learning in this way because they are used to monitoring the students' curricular adherence, including meeting specific standards and ensure proper pacing (Wyatt \& Chapman De Sousa, 2017). Previous work has found that learning to use the CREDE model requires at least a year of intense PD with a CREDE expert (Saunders, Goldenberg, \& Hamann, 1992). In this study, we analyzed our work as CREDE coaches helping teachers navigate integrating the CREDE model into a more traditional approach to teaching, as a follow-up to previous work that demonstrated ways that the CREDE model can fit into rigid and scripted models 
of education (Wyatt, 2014a). However, previous research in CREDE, and more generally, has not positioned PD as a process of brokering two worlds. This framework may be useful for other professional developers working towards culturally compatible education because it acknowledges the tensions and conflict that emerge when two worlds come into contact with each other and makes explicit attempts at problem-solving and negotiation (Bercovitch, 1992; Lindgren, 2016). In this study, we aimed to identify the strategies we used to broker use of the CREDE model within a traditional classroom and the conditions under which we employed the strategies.

\section{Method}

\section{Context of the Study}

This study was conducted in Hawaii, which has been extremely diverse in its culture, languages, socioeconomic status, and religion for centuries. According to the U.S. Census Bureau (2013), 87\% of Hawaii's population is divided between Asians (37.7 \%), Whites (26.6\%), and those who identify as having two or more races (23.1\%). Two other ethnic groups, Native Hawaiians $(10.0 \%)$ and Latino/Hispanics (9.8\%), make up the majority of the rest of the population, thus making Hawaii what anthropologists call "super-diverse" (Vertovec, 2007). In addition to its cultural diversity, one in four people speak languages other than English (Research and Economic Analysis Division, 2016), and many of the early-childhood children are learning multiple languages at a time (Chapman De Sousa, 2017). Combined, Hawaii is incredibly diverse (culturally and linguistically) within its teacher and student population.

\section{Participant}

Participants included 13 in-service teachers who worked at various schools throughout Hawaii. The data from these participants were gathered throughout a year-long CREDE PD course that included full-day workshops, feedback on lesson plans, multiple observations of those lessons followed by coaching sessions, and videotaped lessons with reflections. Ten of the in-service teachers were enrolled in a certificate program on early childhood education. They were licensed prekindergarten to second-grade teachers who worked in various schools throughout the state and were recruited as part of the state's P-20 initiative. The P-20 initiative was aimed at supporting individuals from preschool age through their early career, and as a part of this project, the state was interested in updating teachers' knowledge of early childhood development and providing teachers with strategies in teaching young, culturally diverse learners. As part of the early childhood part of this initiative, the early childhood education certificate program was offered by University of Hawaii, which provided teachers with financial assistance to complete the program. The other three participants were part of a different program of CREDE PD from 2010 through 2011 at the same university. Both groups served highly diverse students, and attempted to implement the CREDE model into their scripted programs.

Each teacher participated in five to six coaching cycles across the year of participation, with each cycle consisting of the following steps: (1) teachers' submission of a lesson plan, (2) coach's feedback on the lesson plan, (3) the coach's observation of the teacher teaching for 60-90 min, (4) a 30-min coaching conversation following the observed lesson, (5) teacher's reflection on the lesson, and finally, (6) the coach's feedback on the teacher's reflection. Additionally, spread out across the year, the teachers were videotaped three times, given a copy, and then asked to reflect on their ability to incorporate the CREDE model into their instruction. These written reflections were then assessed by the coach, as a way to provide the teacher with additional feedback.

\section{Role of the Researchers}

This study made use of what is known as practitioner inquiry (Cochran-Smith \& Lytle, 2009), which positions the practitioner as both a researcher and knower of practice in an effort to improve one's work. Although there are many forms of practitioner inquiry, we borrowed some of the approaches 
and orientations from participatory action research (Whyte, 1991). Specifically, we feel our teachers

should not be treated as subjects of research, but as collaborators in the process of discovery and process/product improvement. In this study, we wanted to understand what we were doing, what was influencing our decisions, and contemplate how we might improve in helping teachers implement culturally compatible education. Using this perspective, we viewed our teachers as collaborators in the process of understanding our work as coaches.

As researchers, we both have doctorates in educational psychology and work in higher education to improve the educational practices of professionals. We are also seasoned CREDE teachers and coaches who have worked in a variety of K-12 educational settings both across the United States and internationally. At the time of the study, we were a part of a large program of PD implemented across the state to implement the CREDE model in early childhood classrooms. The first author was the lead instructional coach for CREDE's overall PD program and helped to create a trainer-oftrainers model for other CREDE coaches. The second author had previously completed the University's CREDE PD program, applied it to her own classroom, and later became faculty at the University.

Although we trained other coaches into using the CREDE model, until this point, it had not occurred to us to analyze our own work as coaches. Any previous discussions on coaching remained at a practical level, focusing on what to do if there were misconceptions about the CREDE standards, how to engage in collaborative lesson planning with teachers, and ways to scaffold teachers' implementation of the model over time. The analysis involved in this study was an attempt to push our understanding of our own work further by identifying why we made the decisions that we did in our work with teachers.

\section{Data Sources}

Data sources included five types of documents collected as part of the teachers' participation in the CREDE PD: (a) teachers' lesson plans, (b) our feedback on the teachers' lesson plans, (c) our observational notes for each CREDE lesson, (d) teachers' reflections on their lesson, and (e) our feedback on teachers' reflections. We anticipated that the teachers' lesson plans and their coaching reflections would provide insight into how teachers thought about and attempted to integrate CREDE with standardized curricula and more traditional models of education. We also anticipated that our feedback would provide insight into the ways we helped teachers mediate the tensions and conflict in planning. We thought our observational notes would provide a record of where and how we provided mediation as teachers implemented both models.

\section{Data Analysis}

The goal for this analysis was to identify the brokering strategies we used in helping teachers change their instruction from a traditional model of teaching to one that was culturally compatible for their diverse groups of students. We used Vygotsky's (1978) sociocultural theory as an analytical lens because of its emphasis on the social construction of knowledge and the role of experts in the learning process. Sociocultural theory underscores the importance of interactions between novices and experts to make sense of the mediation process. In this study, we assumed that documents would reflect social interaction and mediation that teachers experienced with the coach in implementing the CREDE model and reveal the teachers' changing understanding of the CREDE model.

Each coach coded half of their own data and half of the other coach's data to mitigate potential bias. Data were analyzed using a priori coding developed out of the cultural brokering literature from anthropology, tourism, business, and the health sciences. The initial codes were balancing 
expectations, community versus nation oriented, employing cultural expertise, empowerment strategies, helping teachers see impact, negotiation, and suggesting diverging / contradictory behaviors. Initially, a full data set from one teacher was coded using these predetermined codes. The first round of analysis yielded only $42 \%$ agreement between the two researchers. Discrepancies were discussed and codes were revised. The second round of analysis yielded $62 \%$ agreement. Again, discrepancies were discussed and codes revised until the researchers reached 100\% agreement. Thereafter, we randomly divided the remaining data and independently coded them. Once the data were coded, we used constant comparative analysis and cross-case analysis (Glaser \& Strauss, 2009) to look for patterns in our use of brokering strategies to help teachers adopt the CREDE model.

Although practitioner inquiry uses similar methods of data collection and analysis to other qualitative forms of research, rigorous forms of trustworthiness are not expected at the same level (Cochran-Smith \& Lytle, 2009). However, we endeavored to ensure trustworthiness by engaging in reflexivity throughout the data collection and analysis process. To accomplish this, we posed questions of ourselves and each other that allowed for exploration of our roles as coaches in these highly diverse settings. Answers to these questions helped frame our analysis and make sense of the data. For example, in both the act of coaching and in the process of analysis, we asked ourselves questions such as these: Who am I as a coach? What am I assuming about the teacher, the students, and the classroom in which the teacher works? What are the implicit assumptions I am making about the school's curriculum? And, how do my efforts connect to the larger efforts underway in the community, school, in this specific classroom? These questions helped us to see ourselves as both practitioners and researchers in our settings.

\section{Results}

The results of this study demonstrated that we shifted our strategies depending on teacher preferences, classrooms, and curricular constraints. In situations where there were barriers to using the model, such as expectations for strict adherence to curriculum, apprehension from the teacher, or constraints on time, we used more direct methods for helping teachers see where they could leverage change. In situations where there were fewer barriers and teachers expressed a desire to change their practice to meet students' needs, we used more indirect methods and allowed the teachers to discover where and how the model may be implemented. The findings are organized according our brokering strategies. In the following examples, we used pseudonyms, Sara and Rose, to refer to ourselves.

The results indicated that when teachers were open to implementing the CREDE model, we used employing cultural expertise and negotiation as brokering strategies. These strategies invited teacher participation in identifying ways to integrate the CREDE model into their current practice. However, when teachers were hesitant and unsure if they should make drastic changes to their teaching or curriculum, we used more direct approaches, including balancing expectations and helping teachers see the impact. These strategies encouraged teachers to replace aspects of one model for another to reach the teachers' goals. Regardless of the classroom, we employed empowerment strategies and developing teachers as cultural brokers throughout the coaching process to redefine teachers' understanding about teaching culturally and linguistically diverse students.

\section{Cultural Expertise Strategy}

Employing cultural expertise is when a cultural broker uses their previous experience to facilitate or broker change. This strategy positions the coach as someone who has experienced and can go between "two worlds" or educational approaches. We used this strategy to support highly motivated teachers who were receptive to the CREDE model, but felt nervous about making changes. In relation to the other strategies, employing cultural expertise provided an indirect way of encouraging 
teachers to change their practice. It had many forms, but often took on a storytelling element in which we recounted past experiences to highlight important aspects of the pedagogy.

For example, to help assuage teachers' fears, Rose shared her experiences as a CREDE teacher, recollecting how she incorporated students' ideas for future instruction. Her goal was to motivate teachers to adopt similar strategies and therefore replace some of the traditional ways of teaching with the CREDE model. In her interaction, Rose encouraged the teacher to adopt the practice of soliciting ideas from her students, an aspect of the CREDE model that facilitates the disruption of power between teachers and students, and at the same time also provide a way for students to have their ideas represented in the curriculum.

We also used our prior experiences as CREDE coaches to demonstrate cultural expertise. By referencing our work with other teachers, we positioned ourselves as experts in helping others move between "two worlds." For example, in response to Melia's lesson plan, Sara tried to convince Melia of the need to make the content relevant for her students by helping the teacher understand that students don't come to school knowing academic content, which in this example is addition. Rather, they come in with personal experiences and knowledge form their home, school and community that can be used to create a bridge to understand content. In the following example, Sara highlighted the years of coaching she did under the former Hawaii Content and Performance Standards (HCAPS), the precursor to the Common Core Standards, as a way to help mitigate the level of risk the teacher felt. Sara wrote,

I can tell you that I have seen a lot of teachers teach this lesson under HCAPS and the best way to teach it is to ensure deep contextualization. Do yourself and [your students] a favor and make sure they are able to relate to the content of addition. Otherwise, this is going to be a struggle for them.

Sara's HCAPS reference to her earlier experiences accomplished two things in helping the teacher implement the CREDE model. It highlighted her longevity as someone who had assisted teachers with using culturally compatible education, and referenced the importance of making content relevant regardless of the state standards in place. By using the cultural expertise strategy and drawing on her experience, Sara established that she could be trusted in navigating the process of adopting the pedagogy and communicated that the teacher was part of a movement towards culturally compatible education.

\section{Negotiation Strategies}

When teachers were more reluctant to adopt the CREDE model because they felt accountable to their schools, grade levels, or district policies to implement a specific curriculum or way of teaching, we typically used negotiation. Negotiation is a more direct strategy and was typically used with teachers Janet, Yolanda, and Susan, who had contextual circumstances that mitigated the use of the CREDE model. For example, Janet was working in a fully self-contained special education preschool, in which case much of the negotiation came in the form of suggesting ways the teacher could use the model and take into account her unique setting. Yolanda, a kindergarten teacher, was reluctant to move into the phase of the CREDE model in which a significant part of teaching happens during small group Instructional Conversations. She often referenced her fear of losing control of the class by only working with one group of students at a time. To encourage the teacher, Rose used negotiation, in which she laid out the structure of a potential plan that built upon activities the teacher had already used in a whole-group format. To negotiate the change in the teacher's practice, Rose encouraged her to use the familiar activities and maintain the time block predetermined by the school while implementing the new small group format with an Instructional Conversation. Rose helped this teacher try an unfamiliar approach by encouraging small changes in her practice with 
joint reflection on the outcomes. On the teacher's coaching notes Rose wrote,

It seems they are ready to rotate and [participate in] the activity as an Instructional Conversation (IC) center. You could do your poster with capital and lower case ' $F$ ' with small groups of 4 students. I could see it being a ten-minute IC with four rotations (40 minutes). Maybe have three other centers familiar to children such as your letter book, independent reading, making letters out of clay, etc.

Although Rose's suggestion does not reflect full implementation of the CREDE model, with an emphasis on contextualized and differentiated activities and more flexible use of time, especially in the early childhood context, the example above is provided to show how Rose negotiated use of small group activities with an Instructional Conversation within the context the teacher was already working. Later in the PD, Rose negotiated adoption of other components of the model.

Negotiation was more direct than employing cultural expertise in that Rose gave the teacher specific ideas to try. Rose did not recount her own experiences using CREDE with the intention that it would motivate the teacher to also use the model. Through our analysis of when we used negotiation, we noticed that we often paired the direct suggestion with an explanation of the benefits the teacher or students would receive to encourage teachers' implementation. This strategy was helpful to the teachers who were less confident about the process because they did not need to problem-solve themselves, but could rely on the coach's expertise as a guide.

\section{Balancing Expectations and Helping Teachers See Impact}

In situations where teachers had curricular constraints, we relied on balancing expectations and helping teachers see impact. These two strategies helped teachers attend to the explicit goals of both the CREDE model and the more traditional approach. Goals in a traditional classroom may include strict adherence to the curriculum, spacing to cover lessons, and ensuring all students reach benchmark Standards. Goals from the CREDE model include ensuring the content is relevant, students have ample opportunities to engage in discussion, and students feel they have some control over what they are learning. Our employment of these specific strategies accomplished two things: they helped the teachers achieve the curricular goals set by their school or curriculum, and they helped teachers see the impact of their choices when one model dominated the other.

In cases where teachers felt the need to maintain strict adherence to the curriculum, we focused on helping them develop students' language and literacy skills, an important focus in culturally compatible education. Emphasizing language development was an easy leveraging point because most teachers wanted to support children's knowledge and use academic language. However, this required that we privileged one world over the other. In this case, it was the CREDE model over the traditional approach to teaching that requires turn-taking and attending primarily to the teacher whereas the CREDE model integrates discussions with discourse patterns that are balanced with peer to peer turn taking. The model actively seeks to disrupt power differentials in the classroom to encourage student engagement in conversation, sharing of ideas and language development.

We also focused on the importance of contextualization and lack of personal meaning that students have with traditional classroom activities. Sara drew on studies that asserted culturally and linguistically diverse students are not well served by the educational system because they are not able to identify with the content found in textbooks and other curricular materials (Gay, 1995). She helped teachers see the impact on student learning and engagement when content was couched in ways that were meaningful to students, a process known as contextualization (Wyatt, 2014b).

For example, in responding to Lori's lesson plan, Sara noted that the teacher was emphasizing the use of Common Core in her activities and highlighted that the objective may be too difficult for 
students without finding a way for them to relate to the material. To assist Lori with balancing expectation set by state standards with the goals of the CREDE model, Sara suggested the teacher

integrate both models and make the content relevant to her students. On a lesson plans, Sara wrote, "Common core, huh? ... This objective has a conceptual component, which may be difficult for some students. I hope you have considered how you can contextualize it for them." In this example, by suggesting that Lori include content that was relevant to the students, Sara helped the teacher reach the Common Core objective and also ensure that learning was meaningful to students.

In other examples, Sara helped teachers see the impact of not contextualizing their instruction. In many cases, she pointed out that it would be difficult for the teacher to move the conversational topics to a conceptual level if contextualization was not employed. Sara noted, "It is always best to contextualize [the activity]. If you don't contextualize at the beginning, when they are first introduced to what they are doing, it almost always turns into a teacher center and not an Instructional Conversation." In this example, Sara tried to help the teacher see that not using this CREDE strategy could potentially derail her plans to move students' thinking forward and opportunities for students to contribute to a conversation. These two examples illustrate moments when we helped teachers see the need to integrate the two worlds to achieve their instructional goals.

The brokering strategies of balancing expectations and helping teachers see impact helped teachers either integrate the CREDE model into their instruction or replace aspects of the traditional model. When teachers demonstrated a firm understanding of both the curriculum and components of CREDE, we used balancing expectations. This strategy helped teachers integrate the models simultaneously. When we needed to convince teachers of the merits in implementing the CREDE model, helping teachers see impact was used. In several cases, we accomplished this by helping the teacher see the negative effect that only attending to one model had on student understanding and engagement.

\section{Empowerment Strategies and Teacher as Cultural Broker}

We used empowerment strategies, in the form of feedback and praise to support the teachers' adoption of the CREDE model. For example, on Ricky's lesson plan, Rose wrote, "I love how your activities always have a purpose that is relevant to the children." She wanted to validate the teachers' use of contextualization and therefore praised her efforts to incorporate the CREDE model.

Additionally, we worked to empower the teachers to see themselves as cultural brokers whose role is to help students navigate their education. To accomplish this, we focused on the CREDE model's emphasis on responsive assistance rather than the traditional model's emphasis on maintaining a strict following of the curriculum. Positioning teachers as cultural brokers helped them recognize the importance of not only what they were teaching, but also how they were teaching.

Moments where we helped teachers see themselves as cultural brokers were evident in the feedback we gave to teachers on their lesson plans. Initially, most teachers wrote their lessons in ways that focused on what students would do, using language such as, "In this lesson, the students will..." before describing their anticipated outcomes for students' behaviors, language, and thought processes. This format for thinking about how to teach is a hallmark of traditional programs of teacher training. However, the CREDE model requires that teachers focus on themselves and the responsive assistance they plan to use. To help teachers see the difference between the two educational models' foci, and the need for teachers to be responsive to their diverse students' needs, we positioned teachers as cultural brokers who must assist students with making connections between what is learned in school and the knowledge base they bring with them. In a sense, throughout the coaching process, double brokering was occurring; we were helping teachers bridge 
two instructional paradigms, and the teachers were bridging children's home and school experiences. Emphasizing teachers as cultural brokers was clearly seen in Sara's feedback to Lori on her fifth lesson plan:

In all your descriptions of the Standards, I want you to think less of what the students are going to do and focus on what YOU are going to do. The CREDE model is about you. How will you set up opportunities? How will you assist? How will you assess your students and what will you do with this information? This is the next level of thinking that I am trying to push you into.

In this excerpt, Sara helped the teacher develop a new understanding of how "teaching" is defined in the new approach to education, as a way to empower them to see themselves as brokers. Although our main goal was to help teachers integrate the CREDE model into their classrooms, we also worked to shift teachers' view of themselves and role in teaching diverse students.

\section{Discussion}

Education in the United States is fraught with a one-size-fits-all model of education that places high value on corporate curricula and testing within a value system that typically does not reflect those of our culturally and linguistically diverse students. This educational environment has not served culturally and linguistically diverse students well (Aronson \& Laughter, 2016), and there is ample evidence that these kinds of educational approaches have failed marginalized students and contribute to the widening achievement gaps (Darling-Hammond, 2011). The CREDE model represents one effort among professional developers to combat an educational system that focuses solely on individual achievement and de-contextualized knowledge, by providing opportunities for children to engage in conversations on topics that are culturally and socially meaningful.

As CREDE coaches, we were keenly aware of the larger sociopolitical context in which their teachers taught and the cultural and linguistic needs of the students in these classrooms. Additionally, we understood that a highly diverse classroom environment requires teachers to shift their pedagogical focus and incorporate the needs of their students. For this reason, we began our coaching process by carefully assessing each teacher's classroom, alongside the teachers' readiness and motivation for implementing a new pedagogical model. In doing so, we signaled to the teachers that we understood their working environment and would be sensitive to areas with potential to change and areas of non-negotiation. This sensitivity is important and has been noted elsewhere where brokers have worked to effectively navigate potential conflict and tension (Bercovitch, 1992; Lindgren, 2016). Once we communicated we understood these potential constraints, we helped teachers see the value in using the CREDE model, pointing out moments of increased engagement or learning influenced by the new pedagogical approach. Guiding teachers' focus throughout PD is important because it helps to leverage teacher perceptions of various educational interventions and is linked to both teacher engagement and improvement with the intervention's intended outcomes (LoCasale-Crouch et al., 2016).

This study suggests that teachers' use of the CREDE model may have been influenced by our ability as coaches to help them see the immediate outcomes gleaned from the CREDE model, as a motivator for continued implementation. This finding, that teachers need to see immediate outcomes, should be highlighted in other PD efforts. This study also suggests that the process and delivery of PD should be responsive to teachers' attitudes and contexts. When teachers were more open to the CREDE model, we guided their thinking, and allowed them to draw their own conclusions. However, when the teachers were somewhat guarded about implementing the new model, we needed to use a more direct approach. This finding corroborates recent work that underscores the importance of teacher attitude to the overall success of PD endeavors (LoCasale-Crouch et al., 2016) and the need for coaches to both assess and address teachers' needs in this area. 
The framing of coaches as cultural brokers may help other professional developers better understand their role in PD, particularly in the implementation of culturally relevant education. Clearly, there is growing consensus that PD is an important lever for improving teacher practice in early childhood education, but there is little guidance for professional developers on best ways to deliver it (Schachter, 2015). As practitioners, our collective understanding of what constitutes effective PD lacks what others have deemed "sufficient specificity to guide practice" (Wayne, Yoon, Zhu, Cronen, $\&$ Garet, 2008, p. 470). This assessment is based in part on the fact that theoretical frameworks are often left out of intervention descriptions (Schachter, 2015), in which published studies specify the form of PD used (i.e., coaching), yet do not explicate how theory was used or translated in the PD effort.

In a departure from previous work, this study offers the metaphor or framework of "cultural broker" as a way to think about and frame PD efforts. In the current study, we worked as individuals who could dwell between two educational and pedagogical spaces to help address the tension and conflict teachers experienced in integrating a model of culturally relevant education into their more traditional classroom. By positioning coaches as cultural brokers, PD is understood as a means to help teachers navigate more than one world, where different forms of pedagogy interact and potentially cause tension and conflict, and the coaches' role is to mediate.

Further, the results of this study suggest that in situations of pedagogical tension and conflict, the best response is not to throw one model out in favor of another, but to identify how the models can work in tandem, complimenting each other to reach mutual goals. In some cases, this requires that one world or pedagogical model dominate, at the absolute exclusion of the other, whereas in other cases, one world is foregrounded, with traces of the other informing teachers' decision-making process. Where these models go or how they survive for later emergence, is beyond the scope of this paper. However, thinking about the role of coaches as cultural brokers who must be responsive to the context in which teachers work, may help us understand the importance of addressing the inherent tension and conflict that occurs as teachers strive to implement models of culturally relevant instruction.

\section{References}

Adams, K. M. (1997). Ethnic tourism and the renegotiation of tradition in Tana Toraja (Sulawesi, Indonesia). Ethnology, 36, 306-320.

Aronson, B., \& Laughter, J. (2016). The theory and practice of culturally relevant education: A synthesis of research across content areas. Review of Educational Research, 86, 163-206.

Bercovitch, J. (1992). Mediators and mediation strategies in international relations. Negotiation Journal, 8, 99-112.

Boissevain, J. (1974). Friends of friends: Networks, manipulators and coalitions. Oxford, United Kingdom: Basil Blackwell.

Brown, N. (1992). Beachboys as cultural brokers in Bakau town, the Gambia. Community Development Journal, 27, 361-370.

Brown-Jeffy, S., \& Cooper, J. (2011). Toward a conceptual framework for culturally relevant pedagogy: An overview of the conceptual and theoretical literature. Teacher Education Quarterly, 38, 65-84.

Chapman De Sousa, B. E. (2017). Promoting the contributions of multilingual preschoolers. Linguistics and Education, 39, 1-13.

Cherro Osorio, S. G., \& Best, G. (2015). A case study on culture brokers and their role in tourism management in the indigenous community of Taquile Island in Puno, Peru. International Journal of Tourism Research, 17, $347-355$.

Cochran-Smith, M., \& Lytle, S. (2009). Inquiry as stance: Practitioner research for the next generation. New York, NY: Teachers College Press. 
Cooper, C. R. (2011). Bridging multiple worlds: Cultures, identities, and pathways to college. Oxford, United Kingdom: Oxford University Press.

Cooper, C. R. (2014). Cultural brokers: How immigrant youth in multicultural societies navigate and negotiate their pathways to college identities. Learning, Culture, and Social Interaction, 3, 170-176.

Cooper, C. R., Denner, J., \& Lopez, E. (1999). Cultural brokers: Helping Latino children on pathways towards success. The Future of Children, 9, 51-57.

Darling-Hammond, L. (2011). The flat world and education: how America's commitment to equity will determine our future. New York, NY: Teachers College Press.

Delpit, L. D. (1995). Other people's children: Cultural conflict in the classroom. New York, NY: New Press.

Dover, A. (2013). Teaching for social justice: From conceptual frameworks to classroom practices. Multicultural Perspectives, 15, 3-11.

Gay, G. (1995). Bridging multicultural theory and practice. Multicultural Education, 3, 4-9.

Gay, G. (2000). Culturally responsive teaching: Theory, research, and practice. New York, NY: Teachers College Press.

Gay, G. (2013). Teaching to and through cultural diversity. Curriculum Inquiry, 43, 48-70. doi:10.1111/curi.12002

Glaser, B. G., \& Strauss, A. L. (2009). The discovery of grounded theory: Strategies for qualitative research. New Brunswick, Canada: Transaction Publishers.

Goh, S., Yamauchi, L., \& Ratliffe, K. (2012). Educators' perspectives on instructional conversations in preschool settings. Early Childhood Education Journal, 40, 305-314.

Havik, P. (2013). The colonial encounter revisited: Anthropological and historical perspectives on brokerage. In M. Cardeira da Silva (Ed.), The Jill Dias lessons (pp. 97-111). Lisbon, Portugal: Centro em Rede de Investigação em Antropologia.

Herzog, J. D. (1972). The anthropologist as broker in community education: A case study and some general propositions. Council on Anthropology and Education Newsletter, 3, 9-14S.

Howard, T. (2007). The forgotten link. In J. Jackson (Ed.), Strengthening the African American educational pipeline: Informing research, policy, and practice (pp. 17-36). Albany, NY: State University of New York Press.

Institute of Educational Sciences. (2006). What Works Clearinghouse: Instructional conversation and literature logs. Retrieved July 22, 2008, from http://ies.ed.gov/ncee/wwc/pdf/WWC_ICLL_102606.pdf

Jezewski, M. A. (1995). Evolution of a grounded theory: Conflict resolution through culture brokering. Advances in Nursing Science, 17, 14-30.

Kana'iaupuni, S., Ledward, B., \& Jensen, U. (2010). Culture based education and its relationship to student outcomes. Honolulu, Hawaii: Kamehameha Schools Research \& Evaluation Division.

Kim, J. (2006). Ethnic minority counselors as cultural brokers: Using the self as an instrument to bridge the gap. Compelling Perspectives on Counseling, 16, 77-79.

Ladson-Billings, G. (1994). The dreamkeepers: Successful teachers of African-American children. San Francisco, CA: Jossey-Bass.

Lewis, K. (2004). Instructional aides: Colleagues or cultural brokers? The School Community Journal, 14, 91-112.

Lindgren, M. (2016). Peacemaking up close: Explaining mediator styles of international mediators (Report No. 112). Uppsala, Sweden: Department of Peace and Conflict Research, Uppsala University.

LoCasale-Crouch, J., DeCoster, J., Cabell, S., Pianta, R., Hamre, B., Downer, J., ... Roberts, A. (2016). Unpacking intervention effects: Teacher responsiveness as a mediator of perceived intervention quality and change in teaching practice. Early Childhood Research Quarterly, 36, 201-209. doi:10.1016/j.ecresq.2015.12.022

Lomas, J. (2007). The in-between world of knowledge brokering. BMJ, 334, 129-132. 
Mehan, H. (1979). Learning lessons: Social organization in the classroom. Cambridge, MA: Harvard University Press.

Michie, M. (2014). Working cross-culturally: Identity learning, border crossing and culture brokering. Rotterdam, The Netherlands: Sense Publishers.

Miklavcic, A., \& LeBlanc, M. N. (2014). Cultural brokers, clinically applied ethnography, and cultural mediation. In L. J. Kirmayer, G. Jaswant, \& C. Rousseau (Eds.), Cultural consultation: Encountering the other in mental health care (pp. 115-137). New York, NY: Springer Science and Business Media.

Milosovic, S. (2007). Building a case against scripted reading programs: A look at the NCLB Reading First initiative's impact on curriculum choice. The Education Digest, 73(1), 27-30.

Minervino, S., \& Martin, M. C. (2007). Cultural competence and cultural mediation: Diversity strategies and practices in health care. Translocations: The Irish Migration, Race and Social Transformation Review, 2, 190-198.

Nieto, S. (2000). Placing equity front and center: Some thoughts on transforming teacher education for a new century. Journal of Teacher Education, 51, 180-187.

Orellana, M. F. (2009). Translating childhoods: Immigrant youth, language, and culture. Piscataway, NJ: Rutgers University Press.

Paine, R. (1971). A theory of patronage and brokerage. In R. Paine (Ed.), Patrons and brokers in the East Arctic. Toronto, Canada: University of Toronto Press.

Press, I. (1969). Ambiguity and innovation: Implications for the genesis of the culture broker. American Anthropologist, 71, 205-217.

Research and Economic Analysis Division. (2016). Non-English speaking population in Hawaii. Retrieved from http://dbedt.hawaii.gov/economic/reports studies/non-english-speaking-population-in-hawaii/

Rothstein-Fisch, C., Trumbull, E., \& Garcia, S. (2009). Making the implicit explicit: Supporting teachers to bridge cultures. Early Childhood Research Quarterly, 24, 474-486.

Rueda, R., \& Genzuk, M. (2007). Sociocultural scaffolding as a means toward academic self-regulation: Paraeducators as cultural brokers. Focus on Exceptional Children, 40, 1-8.

Saunders, W., Goldenberg, C., \& Hamann, J. (1992). Instructional conversations beget instructional conversations. Teaching and Teacher Education, 8, 199-218.

Schachter, R. (2015). An analytic study of the professional development research in early childhood education. Early Education and Development, 26, 1057-1085. doi:10.1080/10409289.2015.1009335

Singh, N., McKay, J., \& Singh, A. (1999). The need for cultural brokers in mental health services. Journal of Child and Family Studies, 8, 1-10.

Sleeter, C. (2001). Preparing teachers for culturally diverse schools: Research and the overwhelming presence of whiteness. Journal of Teacher Education, 52, 94-106. doi:10.1177/0022487101052002002

Sleeter, C. (2012). Confronting the marginalization of culturally responsive pedagogy. Urban Education, 47, 562584. doi:10.1177/0042085911431472

Sleeter, C., \& Cornbleth, C. (Eds.). (2011). Teaching with vision: Culturally responsive teaching in standards-based classrooms. New York, NY: Teacher's College Press.

Souto-Manning, M. (2013). Multicultural teaching in the early childhood classroom: Approaches, strategies, and tools, preschool-2nd grade. New York, NY: Teachers College Press.

Szasz, M. C. (1994). Introduction. In M. C. Szasz (Ed.), Between Indian and White worlds: The cultural broker. Norman, OK: University of Oklahoma Press.

Tharp, R. G., Estrada, P., Dalton, S. S., \& Yamauchi, L. A. (2000). Teaching transformed: Achieving excellence, fairness, inclusion, and harmony. Boulder, CO: Westview Press. 
Tharp, R. G., \& Gallimore, R. (1988). Rousing minds to life: Teaching, learning, and schooling in social context. Cambridge, United Kingdom: Cambridge University Press.

U.S. Census Bureau. (2013). State and county quick facts. Retrieved October 3, 2014, from http://quickfacts.census.gov/qfd/states/15000.html

Vertovec, S. (2007). Super-diversity and its implications. Ethnic and Racial Studies, 30, 1024-1054. doi:10.1080/01419870701599465

Vygotsky, L. S. (1978). Mind in society: The development of higher psychological processes. Cambridge, MA: Harvard University Press.

Wayne, A., Yoon, K., Zhu, P., Cronen, S., \& Garet, M. (2008). Experimenting with teacher professional development: Motives and methods. Educational Researcher, 37, 469-479.

Weiler, B., \& Yu, X. (2007). Dimensions of cultural mediation in guiding Chinese tour groups: Implications for interpretation. Tourism Recreation Research, 32, 13-22. doi:10.1080/02508281.2007.11081535

Whipp, J. (2013). Developing socially just teachers: The interaction of experiences before, during, and after teacher preparation in beginning urban teachers. Journal of Teacher Education, 64, 454-467. doi:10.1177/0022487113494845

Whyte, W. F. (1991). Participatory action research. Thousand Oaks, CA: Sage Publications Inc.

Wolf, E. (1956). Aspects of group relations in a complex society: Mexico. American Anthropologist, 56, 10651078.

Wyatt, T. R. (2011). Atuarfitsialak: Greenland's cultural compatible reform. International Journal of Qualitative Studies in Education, 25(6), 1-18.

Wyatt, T. R. (2014a). Teaching across the lines: Adapting scripted programs with culturally relevant/responsive teaching. Pedagogy, Culture \& Society, 22, 447-469.

Wyatt, T. R. (2014b). Understanding the process of contextualization. Multicultural Teaching and Learning 10, 111-132. doi:10.1515/mlt-2013-0026

Wyatt, T. R., \& Chapman De Sousa, E. (2017). Teaching as interaction: The challenges of transitioning teachers' instruction to small groups. Early Childhood Teacher Education, 45, 61-70.

Yamauchi, L., Im, S., Lin, C., \& Schonleber, N. (2013). The influence of professional development on changes in educators' facilitation of complex thinking in preschool classrooms. Early Child Development and Care, $183,689-706$.

Yamauchi, L., Im, S., \& Schonleber, N. (2012). Adapting strategies of effective instruction for culturally diverse preschoolers. Journal of Early Childhood Teacher Education, 33, 54-72.

Yohani, S. (2013). Educational cultural brokers and the school adaptation of refugee children and families: Challenges and opportunities. International Migration \& Integration, 14, 61-79. 
The Journal of Educational Research and Practice provides a forum for studies and dialogue that allows readers to better develop social change in the field of education and learning. Journal content may focus on educational issues of all ages and in all settings. It also presents peer-reviewed commentaries, book reviews, interviews of prominent individuals, and additional content. The objectives: We publish research and related content that examines current relevant educational issues and processes aimed at presenting readers with knowledge and showing how that knowledge can be used to impact social change in educational or learning environments. Additional content provides an opportunity for scholarly and professional dialogue regarding that content's usefulness in expanding the body of scholarly knowledge and increasing readers' effectiveness as educators. The journal also focuses on facilitating the activities of both researcher-practitioners and practitioner-researchers, providing optimal opportunities for interdisciplinary and collaborative thought through blogging and other communications.

Walden University Publishing: http://www.publishing.waldenu.edu 